\title{
THE USE OF MICROSEISMS IN HURRICANE DETECTION
}

(Progress-report based on a report of the Navy Department released November 15, 1945, with additional remarks by H. T. Orville, Captain, U. S. N., and by B. Gutenberg, California Institute of Technology)

At the outbreak of the war, the collection, correlation, and administration of the Hurricane Weather Service was in the hands of the United States Weather Bureau, assisted by weather-reports as practicable from the Army Air Forces and the United States Navy. However, the Hurricane Weathor Service felt keenly the lack of usual weather-reports because wartime-restrictions, with radio silence on ships, and with ships proceeding in convoys rather than at random over the ocean, had deprived weather-forecasters of weather reports over vast ocean-areas which were normally obtained from merchant-ships and other sources.

The absence of these reports from ships at sea had left unreported vast expanses of ocean where destructive storms might easily form and attain dangerous proportion. Thus, wartime-demands for accurate aerological data over these vast expanses created a problem of major proportions for the Armed Forces and the United States Weather Bureau. The Joint Meteorological Committee, a working sub-committee for the Joint Chiefs of Staff, considered the problem.

Some evidence of the use of microseisms by European scientists existed in their correlation wilh intense atmospheric storms. As early as 1909, reports of some application in this field was published at Apia [see 1 of "References" at end of report]. W. C. REPETTI believed that a correlation existed between microseisms recorded on the seismographs in Manila and intense storms. There also was evidence of attempts at correlation of seismograph-readings and storms in India.

A study of microseisms was made at the St. Louis University [1] during the last half of 1938 where specially designed seismographs were used. With this special arrangement it was possible to determine the direction of the incoming microseismic waves. In several instances directions were secured and these directions often polnted toward a deep low-pressure area. The hurricane of September, 1938, which passed along the East Coast caused very large microseisms from which bearings were obtained for three days. As the hurricane gradually moved upward along the coast, the bearings, as obtained, shifted with the passage of the storm. As a result of this short researchperiod, it was tentativcly concluded that a direct relationship exists between microseisms and barometric low-pressure areas.

Similar investigations had been made in Göttingen, Germany [2] where up to four stations, with distances between $3-1 / 2$ and $6-1 / 2 \mathrm{~km}$ were used. There, too, the microseisms seemed to radiate from low-pressure areas.

As a result of the findings at the St. Louis University, the Naval Aerological Service under the gudance of H. T. ORVILLE, Captain, U. S. N., became interested, during the early part of the War, in microseisms and their relation to severe atmospheric storms, such as hurricanes. It was visualized that the seismograph could provide methods whereby the path of destructive hurricanes could be followed from day to day even though the centers were several thousand miles away. This was a tremendously significant possibility.

Thus, after due consideration of the problem, outlined above, the Joint Meteorological Committee recommended and it was declded that the Navy would pursue this method of attack, and keep the Joint Meteorological Committee, which is composed of Army, Navy, and Weather Bureau representatives, informed of results.

Thereafter, the Navy organized a program which combined three methods for bridging the gap in the need for weather-reports from vital operational areas associated with hurricane-tracks. The first was the use of weather-reconnaissance squadrons of multi-engined aircraft designed to search out storm-centers (see Fig. 1), the second was the utilization of radar for the detection of storm 
centers (see Fig. 2); the third was an aggressive research-program designed to evaluate microseismic activity in the location of severe atmospheric storms (see Figs. 3 and 4). Thus, the United States Navy commenced what is to be the first practical application of the use of seismology in the tracking of severe atmospheric storms.

Accordingly, to implement the microseismic research, plans were formulated in 1943 for the establishment of a departmental research-project of this nature by the Navy Department at the Naval Operating Base, Guantanamo Bay, Cuba. M. H. GILMORE, Lieutenant Commander, U. S. N. R., a seismologist with considerable practical experience in the field of petroleum-discovery through the use of the seismograph, was designated as Officer in Charge of the project. In this

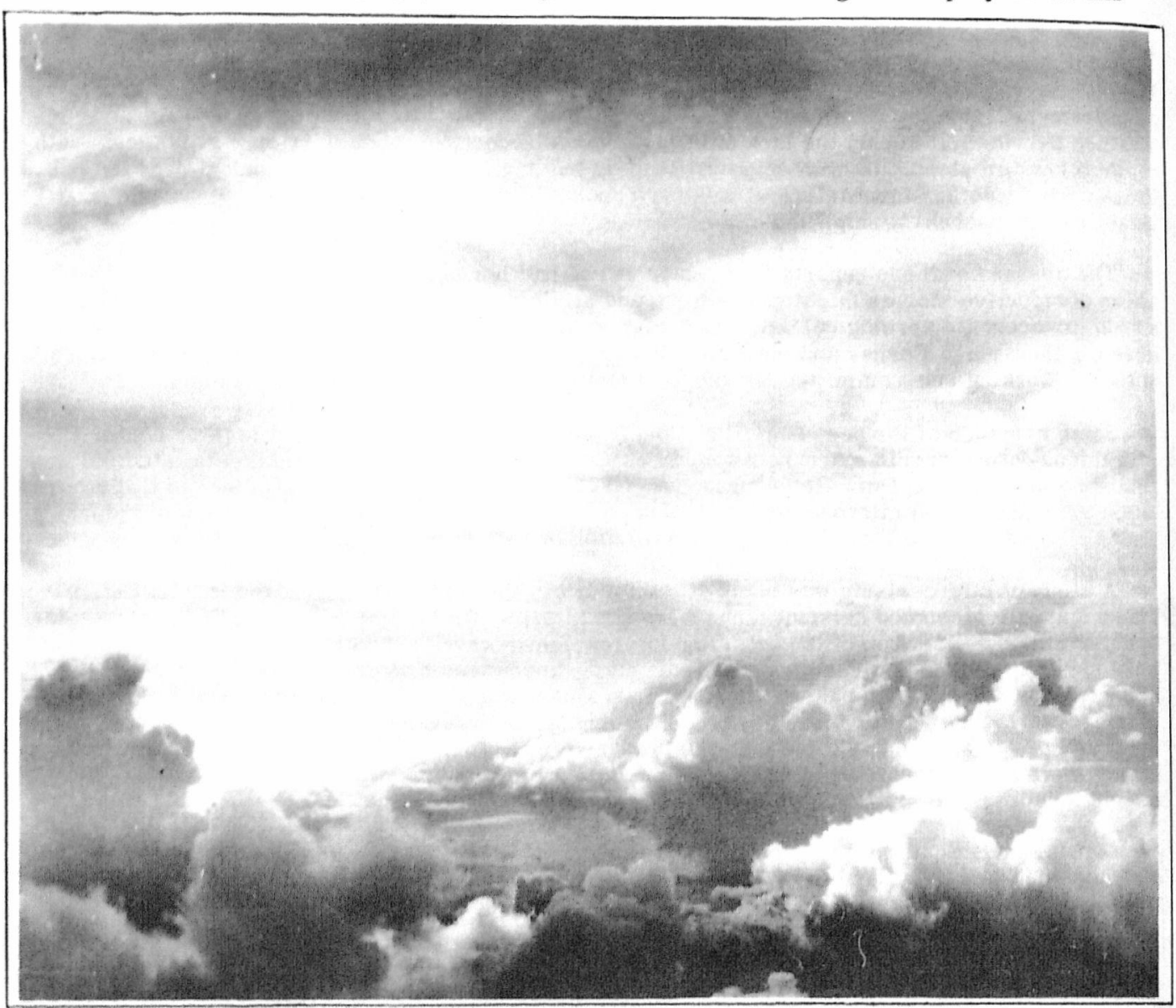

Fig. 1--Eye of a hurricane as it appeared from an airplane

capacity, GILMORE visited instrument-manufacturers, arranged contracts for procurement of equipment, and in early 1944 supervised the installation of the first naval hurricane microseismic equipment at Guantanamo Bay, Cuba. This microseismic station consisted of three microseismic vaults equipped with special microseismic equipment designed specifically for use in hurricanedetection.

The tripartite station, as this type of installation is called, has the vaults situated in a triangular pattern. Thus, a microseismic wave originating from some distant source and traveling along the Earth's surface would reach one of the corners of the triangle first, and the other two corners subsequently. By measuring the time-interval between the arrival of this microseismic wave at the three microseismic vaults, the direction of the source can be found, and in addition the amplitude or magnitude of the wave can be measured. Several excellent examples occurred during the 1944 hurricane-season. Data were collected and evaluated by Lieutenant Commander GILMORE and his 
staff of enlisted assistants. The data indicated a high degree of correlation between microseismic activity and intense atmospheric storms, and in addition indicated that the origin of these microseismic waves could be determined. However, inasmuch as the project only contained one tripartite station, these results were considered highly significant but inconclusive, since triangulation of bearings were needed for accurate centering of storms.

At a conference in Washington, D. C. in late 1944, where the project was discussed in detail, it was concluded that the limitations of a one-station project made it desirable that two additional stations should be added for the 1945 season. These stations were to be located at Naval Operating Base, San Juan, Puerto Rico, and Naval Air Station, Richmond, Florida. The addition of these stations would permit a check by triangulation on the origin of microseismic waves. It was felt that this would establish conclusively the merits of such an investigation. The recommendation for the addition of these two stations was made by F. A. DAVIDSON, Captain, U. S. N., of the Navy's Hurri-

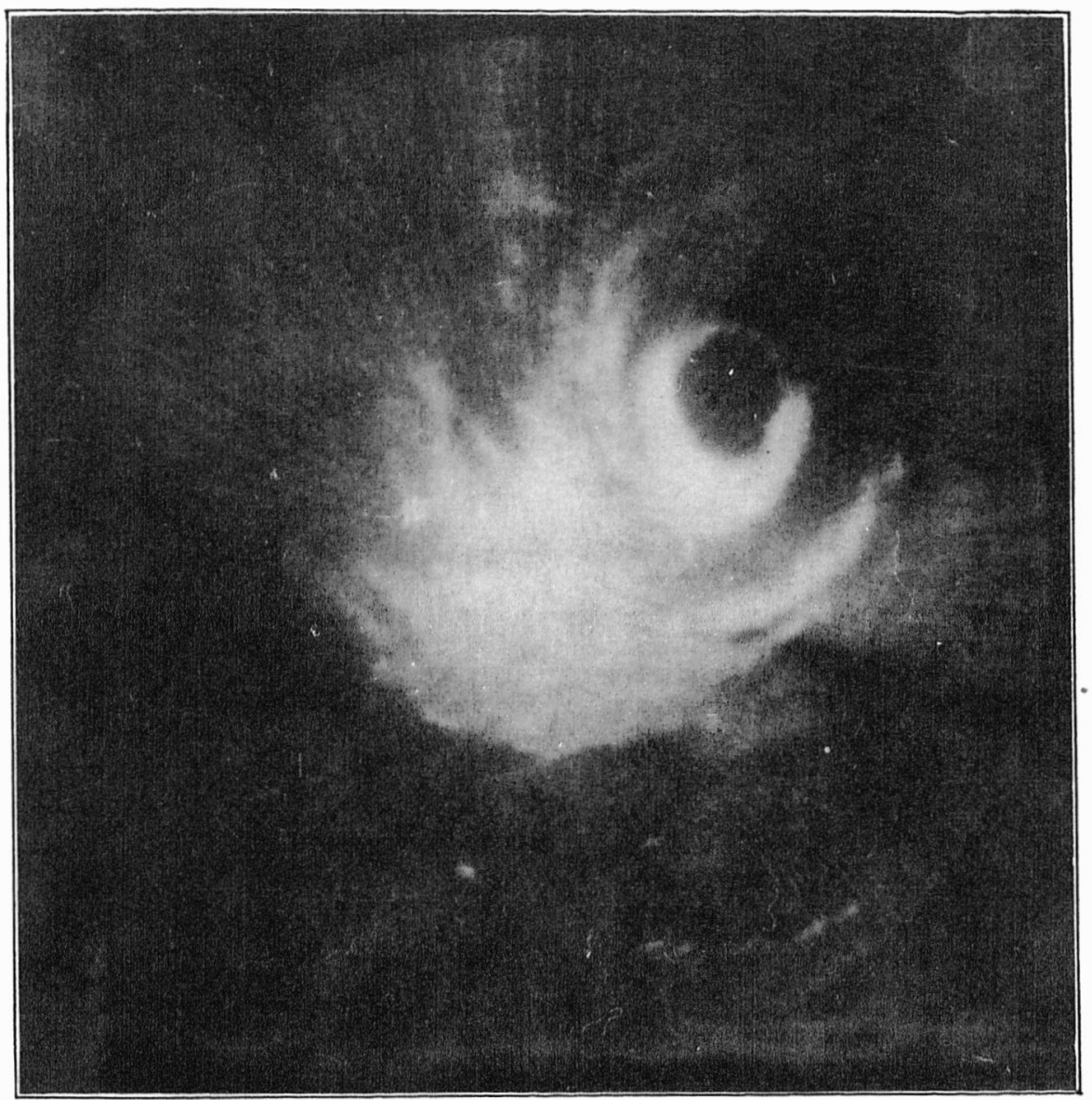

Fig. 2--Eye of a hurricane and precipitation area as observed on the radar-scope

cane Weather Central in Miami, Florida, who took a very keen interest in the project, and materially assisted with the work during the 1944 season by evaluating the results from an aerological viewpoint.

Lieutenant Commander GILMORE again was responsible for obtaining instruments for the outfitting of the additional stations. Equipment was procured, a training program established for additional necessary personnel, and installations completed by the summer of 1945 , at which time everything was in readiness for the hurricane-season. To facilitate the administration of the project and to place operational control near the scene of the project, the entire program was placed under the cognizance of the Commander, Gulf Sea Frontier, W. S. ANDERSON, Vice Admiral, U. S. N. WILLIAM LOVELAND, Commander, U. S. N., the aerological officer on the staff of the 


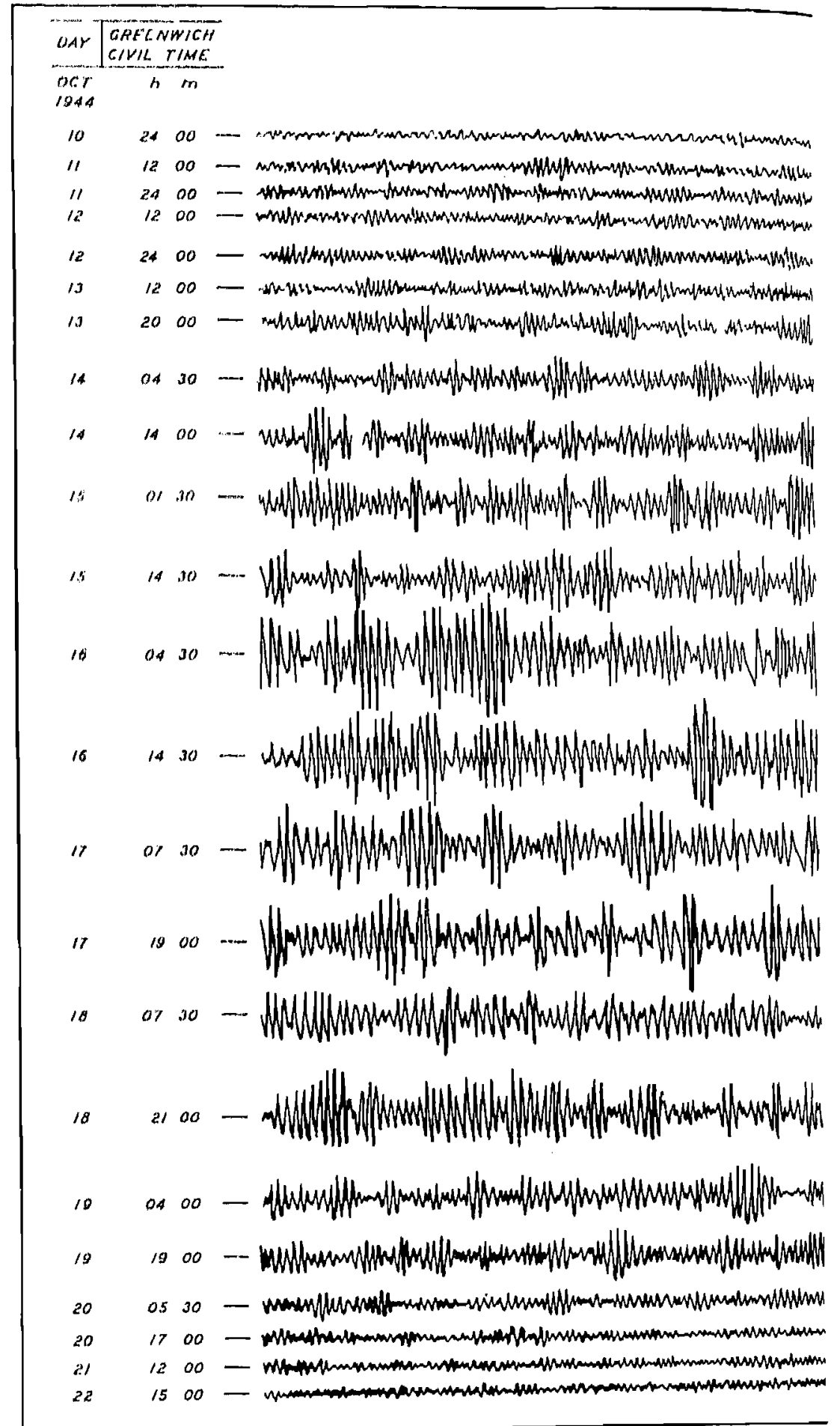

Fig. 3. Amplttudes of microseisms for selected 15 minute intervals during 


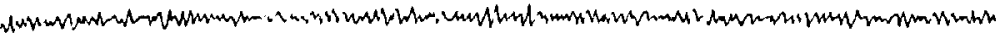

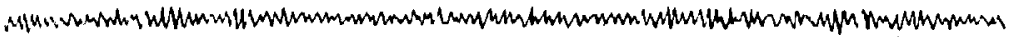

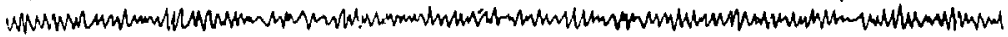

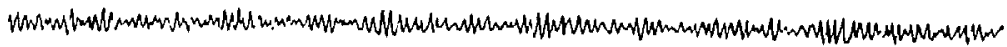

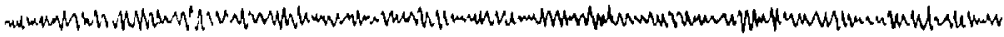

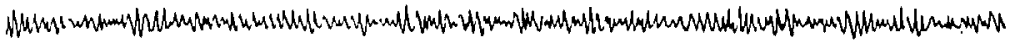

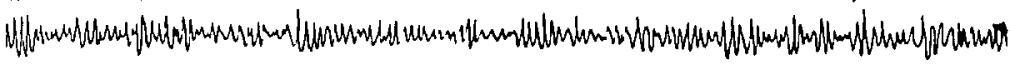

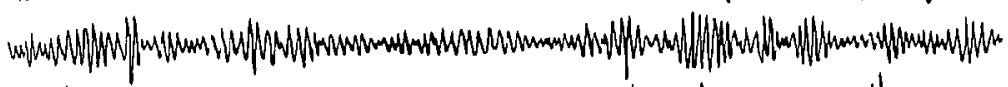

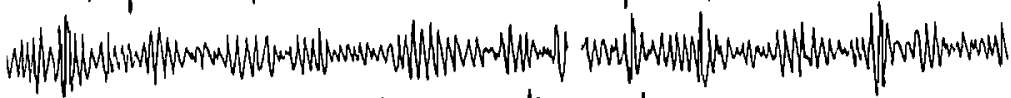

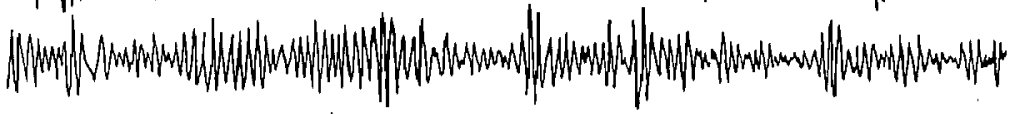

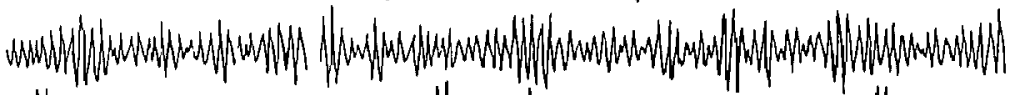

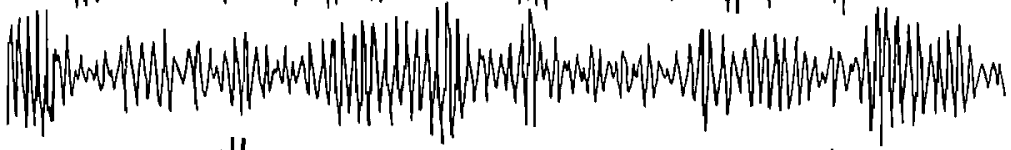

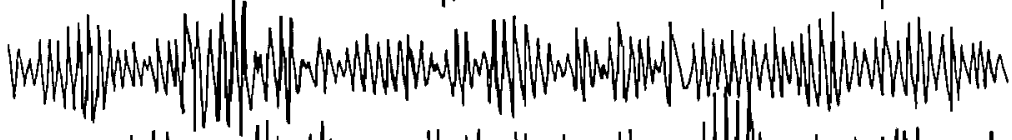

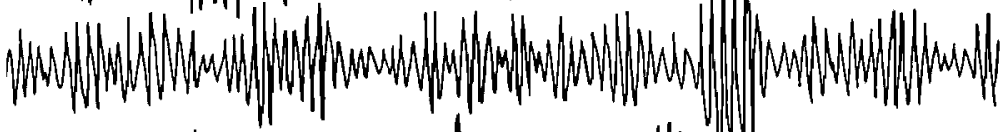

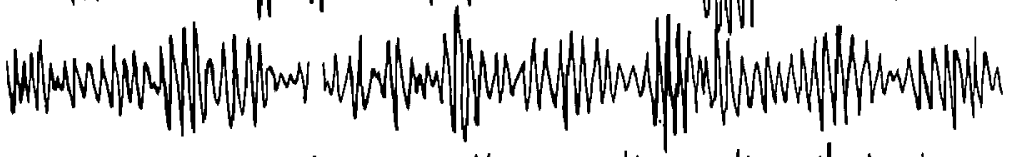

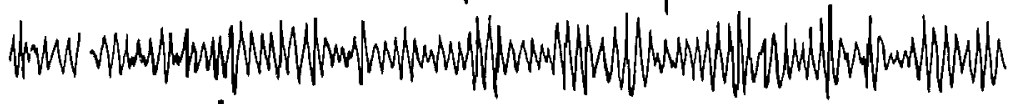

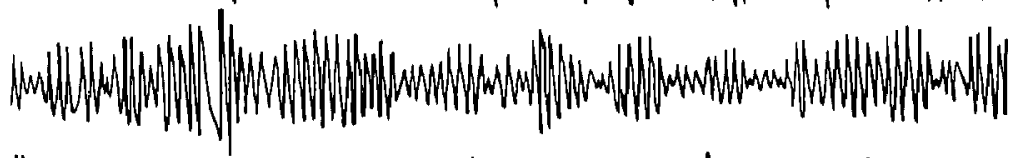

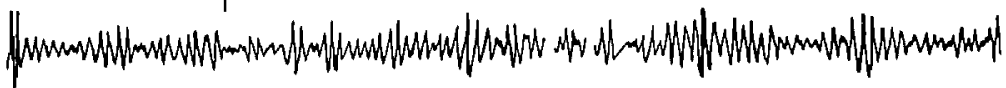

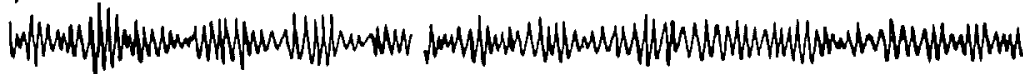

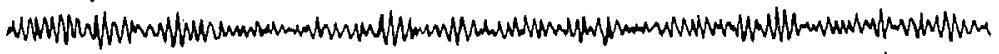

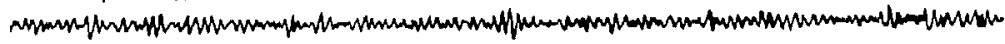

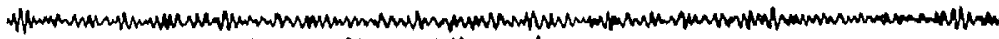
cons

passage of the hurricane of October, 1944, recorded at Guantanamo Bay 


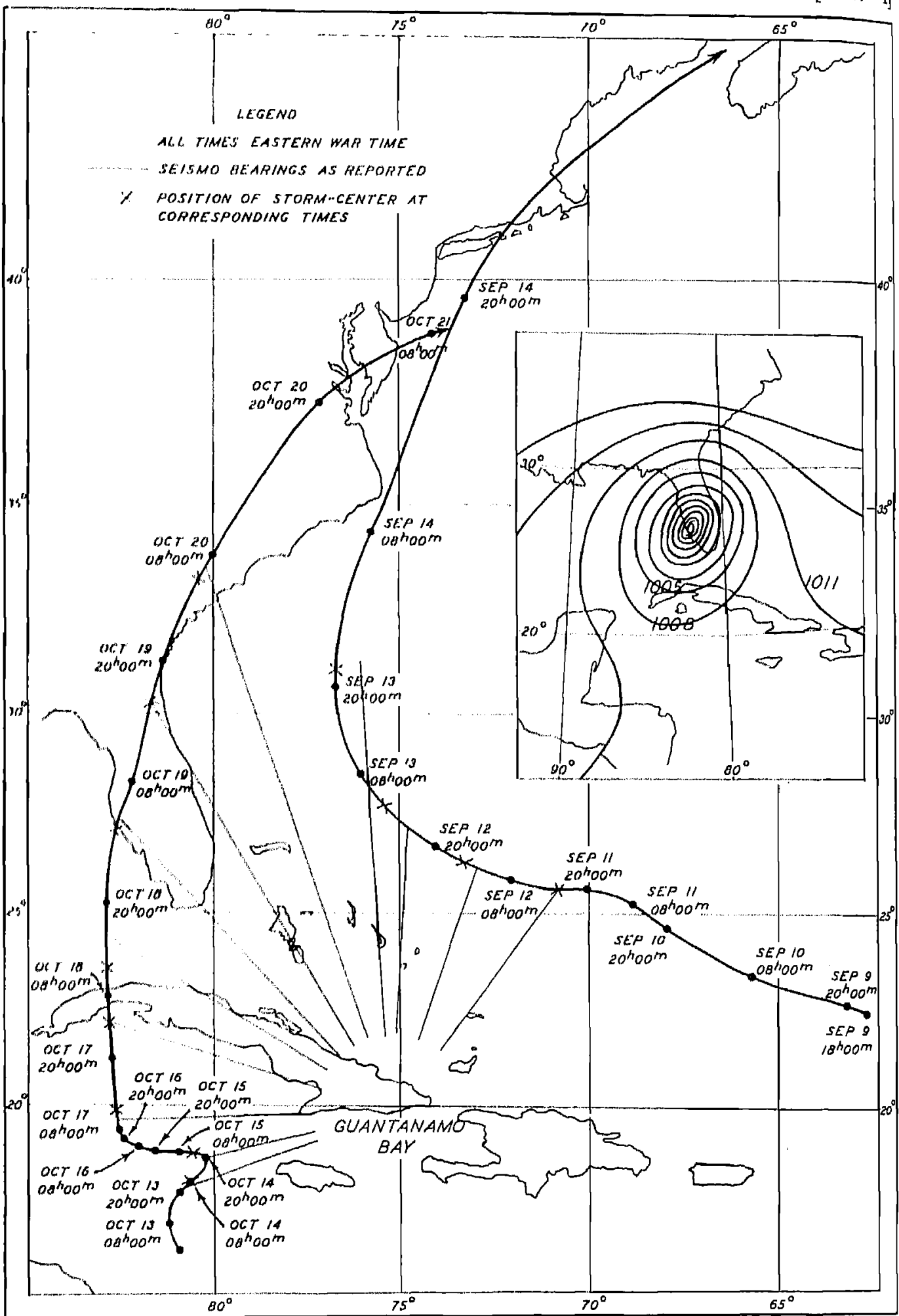

Fig. 4-- Tracks of hurricanes, September 9-15, 1944, and October 13-21, 1944. (Inset) Isobars of October hurricane on entry into Florida 
Commander, Gulf Sea Frontier, assisted in the administrative and operational supervision of the project, and materially assisted the Office of the Chief of Naval Operations in the implementation of this program.

In order to obtain more conclusive results and to establish finally if a correlation did exist between microseisms and severe atmospheric storms, BENO GUTENBERG, in charge of the Seismological Laboratory of the California Institute of Technology, was placed under contract by the Navy Department as technical adviser and consultant for the 1945 season.

In connection with this project, it should be noted that expenses have been relatively small; the installation of a complete seismograph-vault, complete with instrument, costs in the neighborhood of $\$ 8,000$. Thus, the entire program, including equipment and personnel, has cost approximately $\$ 75,000$. When compared with the property-damage that intense atmospheric storms can cause, this expense is insignificant. For example, the great September hurricane of 1938 which lashed the Eastern Seaboard caused property damage in the neighborhood of $\$ 300,000,000$, not to mention considerable loss in life.

During August, 1945, GUTENBERG visited the microseismic project for the purpose of studying data which had been compiled. He said, "The studies which I have made here thus far leave no doubt that the data from microseisms furnish valuable information for the forecasting of hurricanes. The correlation between the microseisms and the storms is convincing." In a later report dated September 6, 1945, GUTENBERG stated, "The writer of the present report has suggested the use of microseisms for the forecasting of storms for many years. The results which he has seen in the Caribbean area exceeded by far his most optimistic hopes, and he is certain that the use of microseismic data in the Caribbean area, as well as in other regions, for the location of hurricanes and the preparation of advisories will aid greatly in reducing the losses of life and damage from hurricanes."

The above conclusions serve to substantiate the faith of the United States Navy in the usefulness of microseisms as a valuable aid in weather-forecasting. However, although the preliminary results have been optimistic in nature, the research-project as established by the Navy Department was to show conclusively the relationship between microseisms and severe atmospheric storms At this time the data for the 1945 hurricane-season are not complete, and consequently the results are as yet considered inconclusive. It is expected that once all the evidence is assembled, a good correlation between the two will have been established, and this method will become a valuable practicable aid to locating, tracking, and forecasting movements of severe tropical storms, thereby effectively contributing to the minimizing of loss of life and property-damage. This will serve as a supplementary support and aid to, but will not replace, the aircraft-reconnaissance squadrons, which have contributed so much to wartime Naval Aerology in locating and tracking hurricanes.

\section{$\underline{\text { References }}$}

[1] For literature on microseisms, see for example: E. RAMIREZ, An experimental investigation of the nature and origin of microseisms at St. Louis, Missourl, Bull. Seis. Soc. Amer., v. 30, pp. 35-84 and 139-178,1940, and L. M. MURPHY, Winter mitroseisms, pp. 19-26, of this issue.

[2] H. D. KRUG, Ausbreitung der natürlichen Bodenunruhe nach Aufzeichnungen mit transportablen Hor izontalseismographen, Zeits. für Geophysik, v. 13, pp. 328-348, 1937.

F. TROMMSDORF, Untersuchungen über die natürliche Bodenunruhe mit transportablen Dreikomponentenstationen, ibid, v. 15, pp. 304-330, 1939.

(Manuscript communicated by BENO GUTENBERG, received December 17, 1945; open for discussion until July 1,1946 .) 